RESEARCH ARTICLE

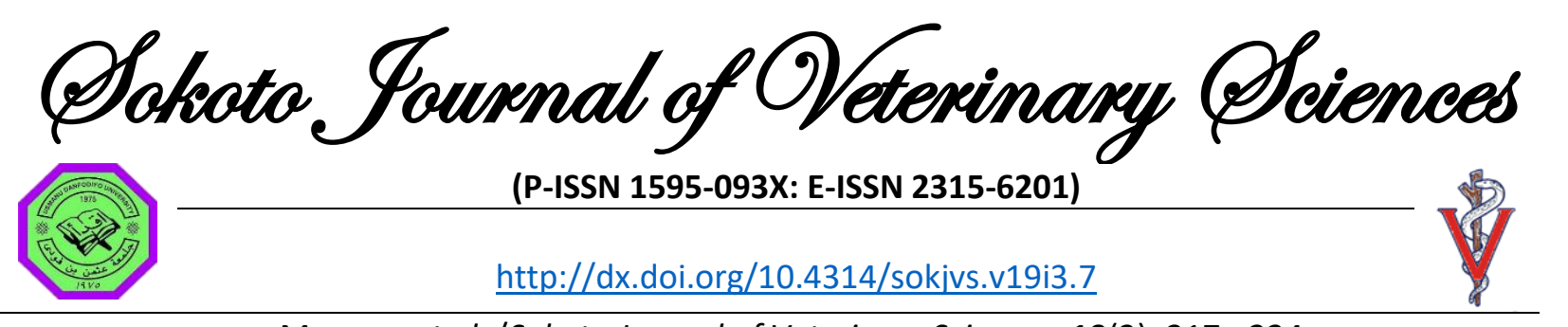

Musawa et al. /Sokoto Journal of Veterinary Sciences, 19(3): 217 - 224.

\title{
Prevalence and molecular identification of Mycobacteria isolated from animals slaughtered at Sokoto modern abattoir, Sokoto State, Nigeria
}

\author{
Al Musawa ${ }^{1 *}$, AA Magaji ${ }^{1}$, MD Salihu$^{1}$, AC Kudi $^{2}$, AU Junaidu ${ }^{1}$, MB Bello $^{3}$, B Garba $^{1}$,

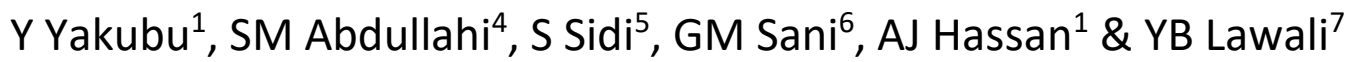 \\ 1. Department of Veterinary Public Health and Preventive Medicine, Usmanu Danfodiyo University, Sokoto, \\ Nigeria \\ 2. Department of Veterinary Public Health and Preventive Medicine, Ahmadu Bello University, Zaria, Nigeria \\ 3. Department of Veterinary Microbiology, Usmanu Danfodiyo University, Sokoto, Nigeria \\ Veterinary Council of Nigeria \\ 5. Department of Theriogenology and Animal Production, Usmanu Danfodiyo University Sokoto, Nigeria \\ 6. Ministry of Animal Health, Husbandry and Fisheries, Kebbi State, Nigeria \\ 7. Ministry of Animal Health and Fisheries Development, Sokoto State, Nigeria
}

*Correspondence: Tel.: +2348036304175; E-mail: aliyu.musawa@udusok.edu.ng

\begin{abstract}
Copyright: (C) 2021
Musawa et al. This is an

open-access article

published under the

terms of the Creative

Commons Attribution

License which permits

unrestricted use,

distribution, and

reproduction in any

medium, provided the

original author and source are credited.
\end{abstract}

Publication History: Received: 11-03-2021

Revised: 05-06-2021

Accepted: 09-06-2021

\section{Abstract}

This study investigated the molecular epidemiology of Mycobacteria isolated from animals slaughtered at Sokoto modern abattoir. During meat inspection, 104 suspected tuberculosis lesions were sampled from a total of 102,681 animals slaughtered between November 2016 and January 2018. These samples were subjected to Ziehl Neelsen staining, followed by culture on Lowenstein-Jensen media. Subsequently, polymerase chain reaction (PCR) and sequencing of the $65 \mathrm{KDa}$ heat shock protein (hsp65) gene were performed to identify and phylogenetically characterize the cultured organisms. Because sequencing of the hsp65 gene was unable to distinguish between Mycobacterium bovis (M. bovis) and $M$. tuberculosis, PCR was performed to amplify a genomic region-specific to $M$. bovis in order to differentiate them from $M$. tuberculosis. Results showed that, 14 samples yielded growth after culture. Furthermore, hsp65 was detected in 9 out of the 14 isolates screened, 5 of the amplicons were successfully sequenced. Similarity search using $\mathrm{NCBI}$ BLAST tool showed the five sequences to share highest identities with Mycobacterium novocastrense (95.99\%), $M$. canettii (94.54\%), and $M$. tuberculosis/M. bovis (100\%). Two out of the 5 isolates were confirmed to be $M$. bovis after PCR amplification using $M$. bovis specific primers. Phylogenetic tree further confirmed the identity of these isolates by placing them close to species of their kind. Further studies should be conducted to establish the transmission dynamics of the zoonotic Mycobacteria between animals and their owners, to facilitate control and eradication of tuberculosis.

Keywords: hsp65 gene, Mycobacteria, Slaughtered animals, Sokoto modern abattoir, Tuberculosis 


\section{Introduction}

Mycobacterium bovis (M. bovis) is the major cause of tuberculosis in cattle and other animals (O'Reilly \& Daborn, 1995). The organism may be transmitted by aerosol or, by ingestion of feed and/or water contaminated with urine of infected animal as well as faecal material or exudates from diseased animals (Thoen et al., 2009). Mycobacterium bovis has one of the broadest host ranges of all known pathogens, having been reported in goat, sheep, pig, horse, cat, dog, fennec fox, bison, badger, wild and feral pig, antelope, camel and primates, among others (Kaneene \& Pfeiffer, 2006). In addition to causing disease in animals, $M$. bovis is one of the species of the Mycobacterium tuberculosis complex that causes tuberculosis in humans, leading to pulmonary or extrapulmonary tuberculosis (Cosivi et al., 1998; Thoen \& Gilsdorf, 2006). Although M. bovis occurs at extremely low levels in industrialized countries, the pathogen still remains a huge public health concern in the developing countries because of poor disease surveillance and control apparatus. According to the Animal Diseases (Control) Act (FRN, 1988), the current control policy for bovine tuberculosis is testing and slaughtering infected animals, with compensation given to the affected farmers. Considering the cost implication of the policy, lack of capacity and/or infrastructural limitations, most African countries are unable to fully implement the Act (Cosivi et al., 1995; Cosivi et al., 1998; Ayele et al., 2004; Renwick et al., 2007). In addition, the frequent conflict between farmers and herders has also resulted in the displacement of large numbers of human and animal populations who may be potential carriers of the bacteria, thereby increasing the transmission (Pembi et al., 2020). Deficiencies in prevention and control have also been attributed to inadequate veterinary and slaughterhouse services, as well as a lack of effective multidisciplinary and multinational cooperation (Cadmus, 2019; Pokam et al., 2019).

The impact of bovine tuberculosis on livestock productivity and the socio-economic wellbeing of rural farmers has been immense. Losses in animals due to tuberculosis are mostly related to condemnation of carcasses during meat inspection, compensation to the owners, increased mortality, and low milk and meat production (Cadmus \& Adesokan, 2009).

Sokoto is the largest and most populous town close to the Illela border of Nigeria and the Niger Republic. Many animals are brought in from neighbouring countries for either slaughter or as draught animals; the origin of these animals is not usually known. Both the nomads and their animals are not being subjected to any form of screening against infectious diseases before being allowed into Nigeria. This poses risk of introducing many pathogens, including the bovine and human tubercle bacilli, across the border.

Previous works have been conducted in the North Western Nigeria to ascertain the status of tuberculosis due to M. bovis (Ajogi et al., 1995; Sonfada \& Garba, 2000; Müller et al., 2009; Musawa et al., 2013). However, there is a need for an appraisal on the status of the disease in the study area because information related to the molecular characterization of the pathogen in the study area is lacking. The present study, therefore, sought to establish the current status of tuberculosis among livestock commonly slaughtered at Sokoto modern abattoir; and to identify the circulating species of Mycobacteria through culture and molecular identification.

\section{Materials and Methods \\ Study area}

The study was conducted at Sokoto modern abattoir located on latitude $13^{\circ} 04.209^{\prime} \mathrm{N}$ and longitude $005^{\circ} 13.416^{\prime} E$. Sokoto metropolis, the capital of Sokoto State, is composed of four Local Government Areas, namely Sokoto South, Sokoto North, DangeShuni and Wamakko. Sokoto State lies on latitude $13^{\circ} \mathrm{N}$ and between longitudes $4.8^{\circ} \mathrm{E}$ and $6.54^{\circ} \mathrm{E}$ in Northwestern Nigeria. The state shares border with the Niger Republic to the north, Kebbi State to the south, and Zamfara State to the east. Based on the 2006 census, Sokoto State has an estimated population of $4,344,399$. It is ranked second in livestock population in the country with approximately 3 million cattle, 4 million goats, 3.85 million sheep, 0.8 million camels, and 1 million poultry (Blench, 1999; SSIPC, 2008).

\section{Study design}

A cross-sectional study approach was employed. All the slaughtered animals were examined at post mortem between November 2016 and January 2018. Animals with gross lesions typical of tuberculosis as described by Thoen et al. (2006) were sampled.

\section{Sample size determination}

Using the formula described by lan et al. (2010), the minimum sample size calculated for cattle was 61 (reported prevalence used was $4.12 \%$ by Musawa et al., 2013), that of camel was 384 (based on assumed $50 \%$ as expected prevalence), while that of small 
ruminants (sheep and goats) was minimum of five (according to the $0.3 \%$ prevalence reported by Cadmus et al., 2008).

\section{Post mortem inspection and sample collection}

Slaughtered animals were subjected to post mortem examination (PM) as described by Demelash et al. (2009). Tissues with single or multiple small foci or tubercles (found in lungs, liver, lymph nodes, spleen and body cavities) were carefully excised together with corresponding lymph nodes into a sterile, labelled polythene bag. The collected samples were immediately transported to the laboratory for freezing until further analyses.

\section{Direct microscopic examination}

Frozen tissue samples were allowed to thaw at room temperature before being homogenized in $0.9 \%$ saline solution. The tissue homogenates were then decontaminated using modified Petroff's method as described by WHO (1998). The decontaminated homogenates were later acid-fast stained and viewed under the microscope as described by WHO (1998). Briefly, a portion of the colony was picked and smeared on a clean, grease-free glass slide, allowed to air dry for 15 minutes and fixed. The smeared slide was then placed on an iron rack and flooded with concentrated carbol fuchsin and gently heated for 5 minutes without allowing it to boil. It was then washed with water and allowed to air dry. After drying, the slide was flooded for 1 minute with $3 \%$ acid alcohol as decolourizer, then washed with water and air-dried. Methylene blue was added for 1 minute as a counterstain. Finally, the smeared slide was washed with water and allowed to air dry.

\section{Cultural isolation}

Two batches of Lowenstein Jensen media slants were prepared; one batch was supplemented with glycerol while the other batch was supplemented with sodium pyruvate (to support the growth of $M$. bovis). Two milliliters $(2 \mathrm{ml})$ of the decontaminated homogenate were spread onto Lowenstein Jensen (LJ) media slants in duplicates with each sample inoculated on $L J$ supplemented with glycerol and $\mathrm{LJ}$ supplemented with pyruvate. The slants were incubated at $37^{\circ} \mathrm{C}$ with daily observation for the first seven days and then weekly for nine to ten weeks, during which growths were observed and recorded. Bacterial colonies on the media were picked using a wire loop and subjected to acid-fast staining and microscopy according to WHO (1998) guidelines.

\section{DNA extraction}

DNA from the cultured bacilli were extracted by thermolysis as previously described by Franco et al. (2013). Briefly, a loopful of the bacterial colony was suspended in $300 \mu \mathrm{L}$ of TE buffer in $1.5 \mathrm{~mL}$ microfuge tube and heat-inactivated for ten minutes. The tubes were immediately frozen at $-21^{\circ} \mathrm{C}$ for 10 minutes before being centrifuged for five minutes at 15,000xg. The supernatant containing the genomic DNA template was decanted using a sterile micropipette into a microfuge tube, and the sediment was discarded. The supernatant was used for polymerase chain reaction (PCR).

\section{PCR amplification of hsp 65 gene}

Four microliters of genomic DNA was added to each reaction tube containing $12.5 \mu \mathrm{L}$ of PCR master mix (containing $20 \mathrm{mM}$ Tris- $\mathrm{HCl}, 22 \mathrm{nM} \mathrm{KCl}, 22 \mathrm{mM} \mathrm{NH} 4 \mathrm{Cl}$, $1.8 \mathrm{mM} \mathrm{MgCl}, 25 \%$ Glycerol, $2 \mathrm{mM}$ dNTPs, $1 \mathrm{X}$ Xylene cyanol, 1X Tartrazine and 25 units/ml of OneTaq ${ }^{\circledR}$ DNA Polymerase) (BioLabs, UK) and $0.5 \mu \mathrm{L}$ each of forward and reverse primers (Table 1). $7.5 \mu \mathrm{L}$ of molecular grade nuclease-free water were added to make the final reaction mix to $25 \mu \mathrm{L}$. The PCR was subjected to an initial denaturation at $94^{\circ} \mathrm{C}$ for 15 minutes, followed by 45 cycles at $94^{\circ} \mathrm{C}$ for 1 minute, $60^{\circ} \mathrm{C}$ for 1 minute and $72^{\circ} \mathrm{C}$ for 1 minute, with a final extension at $72^{\circ} \mathrm{C}$ for 10 minutes (Telenti et al., 1993).

\section{Amplification of $470 b p$ M. bovis species-specific} fragment

As the hsp65 gene cannot be used to clearly distinguish between Mycobacterium bovis and Mycobacterium tuberculosis due to their high genetic similarity, a 470bp segment of genomic DNA that is specific to only Mycobacterium bovis was amplified in order to distinguish it from Mycobacterium tuberculosis. To amplify this fragment, a $25 \mu \mathrm{L}$ reaction mix containing $8 \mu \mathrm{L}$ of DNA template, $12.5 \mu \mathrm{L}$ of master mix (Qiagen ${ }^{\circledR}$ ), and $0.5 \mu \mathrm{L}$ of RNase-free water (Qiagen ${ }^{\circledR}$ ) was prepared. The reaction was subjected to an initial denaturation at $94^{\circ} \mathrm{C}$ for 5 minutes and then 40 cycles of $94^{\circ} \mathrm{C}$ for 1 minute, $58^{\circ} \mathrm{C}$ for 30 seconds, and $72^{\circ} \mathrm{C}$ for 1 minute, and a final extension at $72^{\circ} \mathrm{C}$ for 15 minutes (Romero et al., 1999).

$1.5 \%$ agarose gel was prepared by weighing $1.5 \mathrm{~g}$ of agarose powder into a conical flask and dissolving it by adding $100 \mathrm{ml}$ of TBE buffer, and the mixture was then heated in a microwave oven until it had completely melted. Five microliters of ethidium bromide were added to the molten gel and then poured into gel caster (mounted with comb) and allowed to solidify. PCR products were separated on the $1.5 \%$ agarose gel and immediately visualized using a BioRad GelDoc ${ }^{\circledR}$ imager. 


\section{Sequencing and phylogenetic analysis}

hsp65 gene amplicons were sequenced and aligned using ClustalW program installed in MEGAX software. Subsequently, the best substitution model for phylogeny was determined based on the model with the lowest Bayesian Information Criterion (BIC). Phylogenetic tree was plotted using Maximum Likelihood Method with 1000 bootstrap replicates.

\section{Data analysis}

Data generated in this study were presented in tables and percentages. Fisher's exact test was employed to analyze the association between the occurrence of tuberculosis and species of animals. Values of $p<0.05$ were considered statistically significant.

\section{Results}

Out of the 102,680 animals slaughtered during the study period, 104 animals demonstrated TB lesions based on post mortem meat inspection. However, only 58 of the lesions had acid-fast bacilli following acid-fast staining. This presents an overall prevalence of $0.056 \%$. Table 2 shows the species-specific prevalence of tuberculosis following acid-fast staining of suspected lesions.

Culture and PCR: Out of the 58 acid-fast positive tissue samples, 14 (24.1\%) yielded Mycobacterium like colonies on $\mathrm{L}$ media. Among the 14 samples, nine $(64.3 \%)$ grew on LJ-pyruvate, while five (35.7\%) grew on LJ-glycerol. Nine (64.3\%) were positive for Mycobacterium spp. based on the amplification of the hsp65 gene fragment as shown on plate I.

Sequencing and BLAST results: Out of the nine hsp65 gene PCR products, five were successfully sequenced. Basic Local Alignment Search Tool (BLAST) on the National Center for Biotechnology Information (NCBI) database identified three samples to have aligned

Table 1: List of primers used in this study with either $M$. bovis or $M$. tuberculosis, one other sample aligned with $M$. canettii and the last one with M. novocastrense.

Specific identification of $M$. bovis: As hsp65 gene was unable to clearly distinguish $M$. bovis from $M$. tuberculosis in 3 samples, the $470 \mathrm{bp}$ M. bovis specific segment was successfully amplified in two of these three samples (plate II). The negative sample was from a camel cow, suggesting that it might have been infected with M. tuberculosis.

Phylogenetic analysis: Phylogenetic analysis was able to place the isolates from this study into two distinct clades, tuberculous Mycobacteria (MTBC) and nontuberculous Mycobacteria (NTM). However, amongst members of the MTBC clade, Mycobacterium canettii formed a separate sub-clade that indicates a further genetic difference from the other members, as indicated in Figure 1.

\section{Discussion}

This study provided the prevalence of animal tuberculosis across the four livestock species studied (cattle, camel, sheep and goat). The study also provides the first overall prevalence of animal tuberculosis among all animal species slaughtered in the abattoir within the study period. An overall prevalence of $0.056 \%$ was obtained in this study.

This seemingly low prevalence could be attributed to a large number of animals examined and the long period during which the study was conducted. According to meat inspection records available at the abattoir, more cases of tuberculosis are usually reported annually between May and August. This period coincided with the rainy season in the study location, during which cattle from various places congregate during feeding. Indeed, the majority of the nomads who travelled with the cattle down to the

\begin{tabular}{|c|c|c|c|}
\hline Primer & Sequence (5' to $\left.3^{\prime}\right)$ & Expected band size (bp) & Reference \\
\hline Tb11 forward & ACCAACGATGGTGTGTCCAT & 439bp hsp65 gene & Telenti \\
\hline Tb12 reverse & CTTGTCGAACCGCATACCCT & & $(1993)$ \\
\hline L1 forward & CCCGCTGATGCAAGTGCC & 470bp $M$. bovis fragment & Romero \\
\hline $\mathrm{L} 2$ reverse & CCCGCACATCCCAACACC & & $(1999)$ \\
\hline
\end{tabular}

Table 2. Prevalence of tuberculosis by species of animals slaughtered

\begin{tabular}{lccc}
\hline Species & Number positive & Total slaughtered & Prevalence \\
\hline Cattle & 55 & 62872 & $0.087 \%$ \\
Camel & 3 & 6775 & $0.044 \%$ \\
Small ruminants (sheep \& goats) & 0 & 33033 & $0 \%$ \\
Total & 58 & 102680 & $0.056 \%$ \\
\hline
\end{tabular}

$p$-value $=0.371 ;$ Result for small ruminants (sheep and goats) was not included during the analysis as no positive case was recorded for these species 


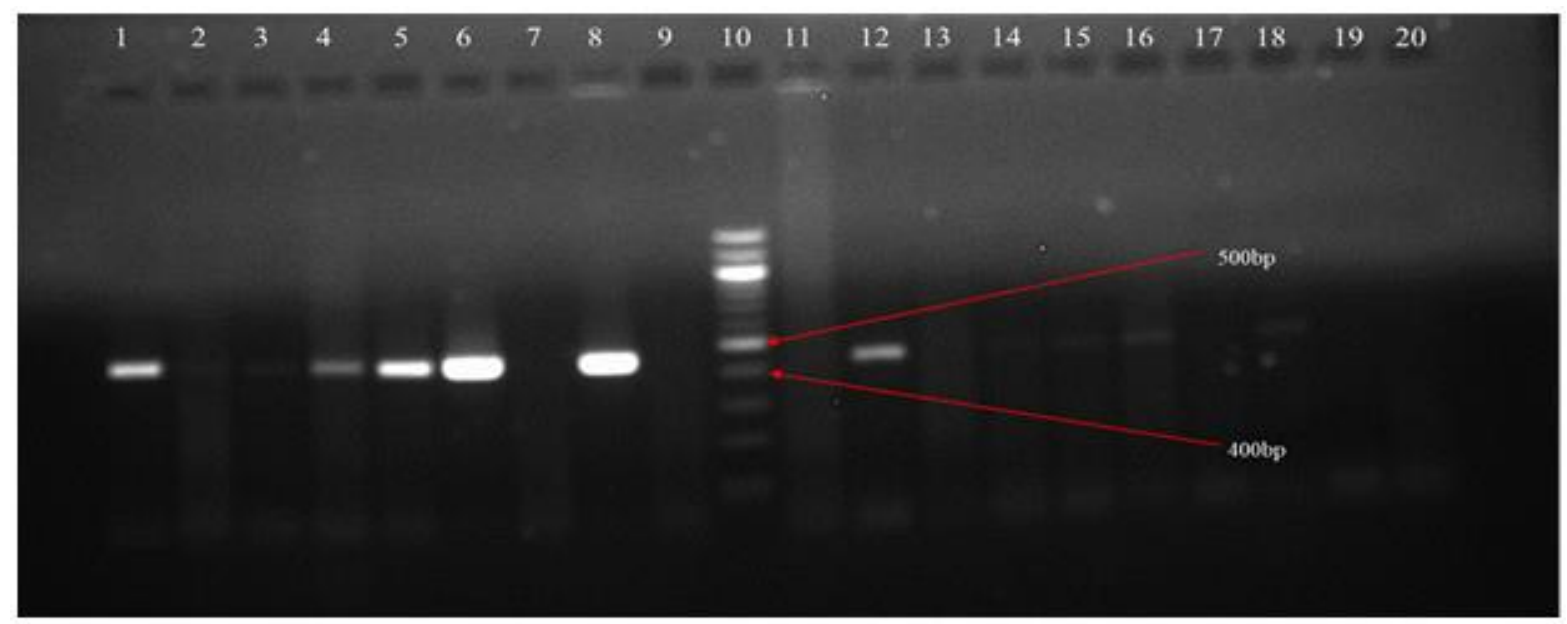

Plate I: Agarose gel image showing amplified 439bp hsp65 gene. Lanes 1, 4, 5, 6, 12, 16 and 18 showing 439bp bands, lane 8 is the positive control ( $M$. bovis BCG); lane 9 is the negative control while lane 10 is the $100 \mathrm{bp}$ molecular weight ladder.

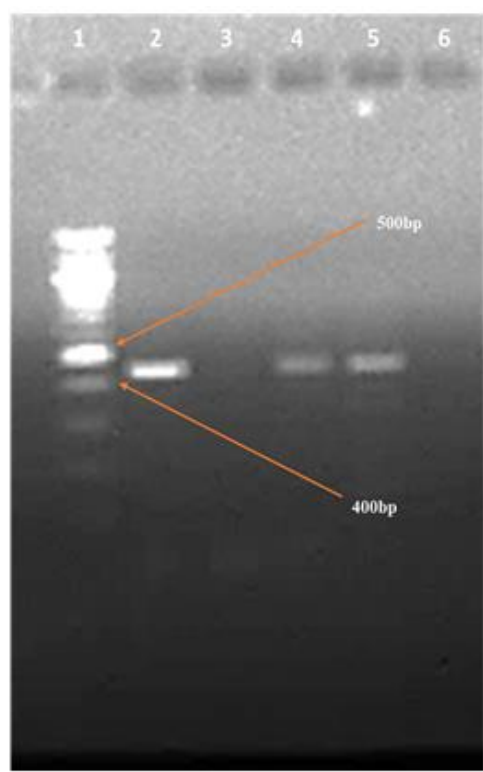

Plate II: Plate II: Agarose gel electrophoresis image of the 470bp $M$. bovis species-specific fragment. Lane 1 showing the $100 \mathrm{bp}$ molecular weight ladder, lane 2 is a positive control $(M$. bovis $\mathrm{BCG})$, lane 3 is the negative control, lanes 4 and 5 showing positive samples, while lane 6 shows a negative sample.

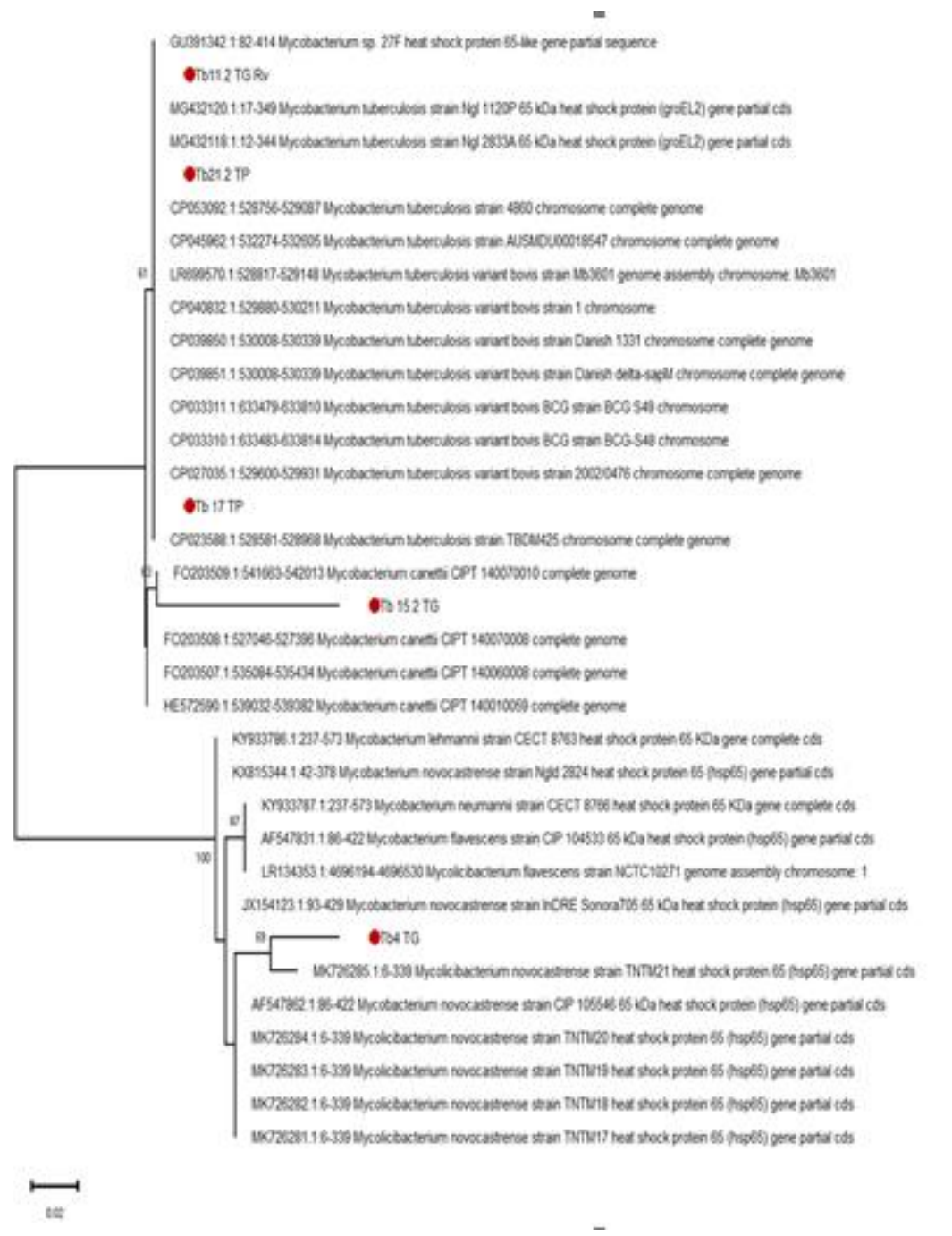

Figure 1: Phylogenetic tree showing the relationship between samples sequenced and some selected references 
southern parts of the country, in search of green vegetation during the dry season in the north, usually return around the rainy season. This nomadism partly explains the relatively low prevalence observed in this study as the study was conducted during the dry season. The low prevalence obtained in this study corresponds to the findings of Ajogi et al. (1995) in Sokoto and Bala et al. (2011) in Maiduguri, who reported prevalence rates of $0.69 \%$ and $0.7 \%$, respectively, based on post mortem meat inspection and acid-fast staining.

Across the different animal species studied, cattle had a higher prevalence $(0.087 \%)$ when compared to camel $(0.044 \%)$. However, no statistically significant association was found to exist between species of animals and tuberculosis $(p>0.05)$. Apart from the larger number of slaughtered cattle, the higher prevalence rate in cattle could be due to host adaptability of $M$. bovis, which is the primary causative agent of bovine tuberculosis. Again, cattle are herded in larger numbers than camels, sheep and goats; therefore, cattle have higher chances of spreading tuberculosis among themselves than camel, sheep and goats (Barlow et al., 1999). Moreover, camelids were not considered highly susceptible to tuberculosis (Wernery \& Kinne, 2012). Prior to the present investigation, a lower prevalence of bovine tuberculosis in this study area had been reported (Dusai \& Abdullahi, 1994; Sonfada \& Garba, 2000). Likewise, a higher prevalence was reported by Musawa et al. (2013) in the study area. These differences may be attributed to variations (similarity or differences) in the sensitivity of the diagnostic tests employed, sample size and improved butcher cooperation in the abattoir.

In this study, a prevalence of $0.04 \%$ for camel tuberculosis was recorded. This seemingly very low prevalence may be due to the assumption that camels are presumed not to be highly susceptible to tuberculosis (Wernery \& Kinne, 2012); however, this does not mean camels do not get infected. Mukhtar (2015) reported an overall prevalence of $30.8 \%$ when he screened for antibodies against $M$. bovis in camels slaughtered in Sokoto abattoir. Surprisingly, Mukhtar (2015) recorded 0\% prevalence when camels were subjected to post mortem meat inspection. Prevalence rates very close to that obtained in this study have been reported. Bala et al. (2011) reported $0.3 \%$ in Maiduguri abattoir and Boukary et al. (2012) in the neighboring Niger Republic reported $0.1 \%$. Higher prevalence of camel tuberculosis (17\%) has been reported in Northern Nigeria (Kudi et al., 2012), $33.5 \%$ in Zamfara (Ahmad et al., 2019) and $16.6 \%$ in
Maiduguri (Abubakar et al., 2012). In Ethiopia, Zerom et al. (2013) reported 12.3\%, while in India Narnaware et al. (2015) reported $19.5 \%$. Our study also incriminated more camel cows with tuberculous lesions when compared to their male counterparts. This could be because more cows of old age are presented for slaughter, as also reported by Kudi et al. (2012), Zerom et al. (2013) and Mukhtar (2015).

This study corroborated previous studies that associated tuberculosis with slaughtered animals in Sokoto. This is the first report of the isolation and molecular identification of $M$. canettii from slaughtered cattle, the potential catastrophe on human health by this organism cannot be overemphasized. Similarly, the emergence of this pathogen away from its known epidemiological location (the horn of Africa) calls for prompt and intensive surveillance and control measures to curb its further spread. Our discovery of $M$. canettii strengthens the suggestion by some scientists on the possible existence of an unknown environmental reservoir. There is, therefore, the need for elaborate research aimed at identifying the reservoir host(s) of this organism with the hope of understanding the transmission dynamics of tuberculosis caused by $M$. canettii.

Finally, an annual statewide survey for animal tuberculosis with the aim of understanding the dynamics of transmission of tuberculosis between animals and humans in the state is strongly recommended.

\section{Conflict of Interest}

The authors declare that there is no conflict of interest.

\section{References}

Abubakar UB, Kudi AC, Abdulkadir Al, Okaiyeto SO \& Ibrahim $S$ (2012). Prevalence of tuberculosis in slaughtered camels (Camelus dromedarius) based on post- mortem meat inspection and Ziehl-Neelsen stain in Nigeria. Journal of Camel Practice and Research, 19(1): 29-32

Ahmad I, Kudi CA, Babashani M, Chafe UM, Yakubu Y \& Shittu A (2019). Tuberculosis in dromedary camels slaughtered in Nigeria: A documentation of lesions at postmortem. Tropical Animal Health and Production, 51(1): 73-78.

Ajogi I, Uko UE \& Tahir FA (1995). A retrospective (1990-1992) study of tuberculosis, cysticercosis and hydatidosis in food animals 
slaughtered in Sokoto Abattoir, Nigeria. Tropical Veterinarian, 13(4): 1-4.

Ayele WY, Neill SD, Zinsstag J, Weiss MG \& Pavlik I (2004). Bovine tuberculosis: An old disease but a new threat to Africa. International Journal of Tuberculosis and Lung Diseases, 8(8): 924-37.

Bala AN, Garba AE \& Yazah AJ (2011). Bacterial and parasitic zoonoses encountered at slaughter in Maiduguri abattoir, Northeastern Nigeria. Veterinary World, 4(10): 437-443.

Barlow AM, Mitchell KA \& Visram KH (1999). Bovine tuberculosis in llama (Lama glama) in the UK. Veterinary Record, 145(22): 639-640.

Blench R (1999). Traditional Livestock Breeds: Geographical Distribution and Dynamics in Relations to the Ecology of West Africa. Overseas Dev. Inst. Portl. House Stag Place London, SW1E 5DP.

Boukary AR, Thys E, Rigouts L, Matthys F, Berkvens D, Mahamadou I, Yenikoye A \& Saegerman C (2012). Risk factors associated with bovine tuberculosis and molecular characterization of Mycobacterium bovis strains in urban settings in Niger. Transboundary Emerging Diseases, 59(6): 490-502.

Cadmus SIB (2019). Bovine Tuberculosis in Nigeria: Historical Perspective, Burden, Risk Factors, and Challenges for Its Diagnosis and Control. In: Tuberculosis in Animals: An African Perspective (AB Dibaba, NPJ Krick, \& CO Thoen, editors). Springer International Publishing AG 2017, Cham, Switzerland. Pp 363-378.

Cadmus SIB, Adesokan HK \& Awosanya AEJ (2008). Public issues and observations made during meat inspection at Bodija municipal abattoir, Ibadan, Oyo state of Nigeria. Nigerian Veterinary Journal, 29(2): 43-47.

Cadmus SIB \& Adesokan HK (2009). Causes and implications of bovine organs/offal condemnations in some abattoirs in Western Nigeria. Tropical Animal Health and Production, 41(7): 1455-1463.

Cosivi O, Grange JM, Daborn CJ, Raviglione MC, Fujikura T, Cousins D, Robinson RA, Huchzermeyer HFAK, De Kanto I \& Meslin FK (1998). Zoonotic tuberculosis due to Mycobacterium bovis in developing countries. Emerging Infectious Diseases, 4(1): 59-70.

Cosivi O, Meslin FX, Daborn CJ \& Grange JM (1995). Epidemiology of Mycobacterium bovis infection in animals and humans, with particular reference to Africa. Revue Scientifique et Technique, 14(7): 733-746.

Demelash B, Inangolet F, Oloya J, Asseged B, Badaso M, Yilkal A \& Skjerve E (2009). Prevalence of bovine tuberculosis in Ethiopian slaughter cattle based on post-mortem examination. Tropical Animal Health and Production, 41(5): 755-765.

Dusai DHM \& Abdullahi DA (1994). Current status of bovine tuberculosis at Sokoto abattoir. Tropical Veterinarian, 12(3): 134-137.

Federal Republic of Nigeria (1988). Animal Disease Control Act 10, 1988. - Law Nigeria lawnigeria.com/LFN/A/Animal-Diseases (Control) Act. http://www.vertic.org/media/National\%20L legislation/Nigeria/NG_Animal_Diseases_Co ntrol_Act.pdf, retrieved 13-01-2021.

Franco MMJ, Paes AC, Ribeiro MG, de Figueiredo Pantoja JC, Santos ACB, Miyata M, Leite CQF, Motta RG \& Listoni FJP (2013). Occurrence of mycobacteria in bovine milk samples from both individual and collective bulk tanks at farms and informal markets in the southeast region of Sao Paulo, Brazil. BMC Veterinary Research, doi.10.1186/1746-6148-9-85.

Ian D, Wayne M \& Henrik S (2010). Veterinary Epidemiologic Research, second edition (Margaret S, editor), AVC Inc. Charlottown, Prince Edward Island, Canada. P. 41.

Kaneene JB \& Pfeiffer D (2006). Epidemiology of Mycobacterium bovis. In: Mycobacterium bovis Infection in Animals and Humans. Blackwell Publishing Limited, Oxford, UK. Pp 34-48.

Kudi CA, Abubakar B \& Awah N (2012). Prevalence of bovine tuberculosis in camels in northern Nigeria. Journal of Camel Practice and Research, 19(1): 81-86.

Mukhtar AU (2015). Seroprevalence of Mycobacterium bovis antibodies in camel slaughtered at Sokoto Abattoir, Nigeria. Master dissertation, Department of Veterinary Public Health and Preventive Medicine, Usmanu Danfodiyo University Sokoto. Pp 60.

Müller B, Hilty M, Berg S, Garcia-Pelayo MC, Dale J, Boschiroli ML, Cadmus S, Ngandolo BNR, Godreuil S, Diguimbaye-Djaibé C, Kazwala R, Bonfoh B, Njanpop-Lafourcade BM, Sahraoui N, Guetarni D, Aseffa A, Mekonnen MH, Razanamparany VR, Ramarokoto $H$, Djønne 
B, Oloya J, Machado A, Mucavele C, Skjerve E, Portaels F, Rigouts L, Michel A, Müller A, Källenius G, van Helden PD, Hewinson RG, Zinsstag J, Gordon, SV \& Smith, NH (2009). African 1, an epidemiologically important clonal complex of Mycobacterium bovis dominant in Mali, Nigeria, Cameroon, and Chad. Journal of Bacteriology, 191(6): 19511960.

Musawa Al, Junaidu AU, Magaji AA, Tambuwal FM, Salihu MD \& Saulawa AM (2013). Prevalence of Mycobacterium bovis in cattle slaughtered at Sokoto Central Abattoir. Bulletin of Animal Health and Production in Africa, 61(2): 215-219.

Narnaware SD, Dahiya SS, Tuteja FC, Nagarajan G, Nath K \& Patil NV (2015). Pathology and diagnosis of Mycobacterium bovis in naturally infected dromedary camels (Camelus dromedarius) in India. Tropical Animal Health and Production, 47(8): 16331636.

O'Reilly LM \& Daborn CJ (1995). The epidemiology of Mycobacterium bovis infections in animals and man: A review. Tuberculosis and Lung Diseases, 76(1): 1-46.

Pembi E, John S, Dumre SP, Ahmadu BU, Vuong NL, Ebied A, Baba UV, Nguyen LE, Amr M, Shusaku H, Nguyen TC, Luis E \& Hirayama K (2020). Impact of political conflict on tuberculosis notifications in North-east Nigeria, Adamawa State: A 7-year retrospective analysis. BMJ Open, 10(9): 17.

Pokam BDT, Guemdjom PW, Yeboah-Manu D, Weledji EP, Enoh JE, Tebid PG \& Asuquo, AE (2019). Challenges of bovine tuberculosis control and genetic distribution in Africa. Biomedical and Biotechnology Research Journal, 3(4): 217-227.

Renwick AR, White PCL \& Bengis RG (2007). Bovine tuberculosis in southern African wildlife: A multi-species host-pathogen system. Epidemiology and Infection, 135(4): 529540.
Romero RE, Garzn DL, Mejia GA, Monroy W, Patarroyo ME \& Murillo LA (1999). Identification of Mycobacterium bovis in bovine clinical samples by PCR speciesspecific primers. Canadian Journal of Veterinary Research, 63(2): 101-106.

Sokoto State Investment Promotion Committee (2008). "Beef you Profit by Investing in Sokoto State Livestock Sector, Sokoto," Pp 18.

Sonfada ML \& Garba SH (2000). A retrospective study of bovine tuberculosis in cattle slaughtered in Sokoto abattoirs. Sokoto Journal of Veterinary Sciences, 2(2): 36-39.

Telenti A, Marchesi F, Balz M, Bally F, Bottger EC \& Bodmer T (1993). Rapid identification of mycobacteria to the species level by polymerase chain reaction and restriction enzyme analysis. Journal of Clinical Microbiology, 31(2): 175-178.

Thoen CO, Lobue P, Enarson D, Kaneene JB \& de Kantor IN (2009). Tuberculosis: a reemerging disease in animals and humans. Veterinaria Italiana, 45(1): 135-181.

Thoen CO, Steele JH \& Gilsdorf MJ (2006). Human tuberculosis caused by Mycobacterium bovis in Latin America and the Caribbean. In: Mycobacterium bovis infection in animals and humans. Blackwell Publishing Limited, Oxford, UK. P. 13.

Wernery U \& Kinne J (2012). Tuberculosis in camelids: A review. Revue et Scientific Technique, 31(3): 899-906.

World Health Organization (1998). Laboratory Services in Tuberculosis Control: Part II: Microscopy. Jotto Associati s.a.s., Biella, Italy. Pp 27-40.

Zerom K, Sisay T, Mamo G, Bayu Y \& Ameni G (2013). Tuberculosis in dromedaries in eastern Ethiopia Abattoir-based prevalence and molecular typing of its causative agents. Small Ruminant Research, Biblioteka Nauki Yadda. 109(2-3): 188-192. 